\title{
Predictors of continuation with olanzapine during the I-year naturalistic treatment of patients with schizophrenia in Japan
}

This article was published in the following Dove Press journal:

Patient Preference and Adherence

I3 December 201।

Number of times this article has been viewed

\author{
Wenyu Ye' \\ Haya Ascher-Svanum² \\ Yuka Tanji ${ }^{3}$ \\ Jennifer A Flynn ${ }^{3}$ \\ Michihiro Takahashi ${ }^{3,4}$ \\ 'Lilly Suzhou Pharmaceutical Co, \\ Shanghai, People's Republic of China \\ ${ }^{2}$ Eli Lilly and Company, Indianapolis, \\ IN, USA; ${ }^{3}$ Lilly Research Laboratories \\ Japan, Eli Lilly Japan KK, Kobe, \\ ${ }^{4}$ Terauchi-Takahashi Psychiatric \\ Clinic, Ashiya, Japan
}

Purpose: Treatment continuation is considered an important measure of antipsychotic effectiveness in schizophrenia, reflecting the medication's efficacy, safety, and tolerability from both patients' and clinicians' perspectives. This study identified characteristics of patients with schizophrenia who continue olanzapine therapy for a 1-year period in Japan.

Methods: In a large $(\mathrm{N}=1850)$, prospective, observational study, Japanese patients with schizophrenia who initiated treatment with olanzapine were followed for 1 year. Baseline characteristics were compared using $t$-tests and chi-square tests. Stepwise logistic regression was used to identify independent baseline predictors of treatment continuation.

Results: Most patients (68.2\%) continued with olanzapine therapy for the full 1-year study period, with an average duration of $265.5 \pm 119.4$ days. At baseline, patients who continued were significantly more likely to be male, older, and inpatients; have longer illness duration, higher negative and cognitive symptoms, better health-related quality of life, and prior anticholinergic use. Continuers were significantly less likely to engage in social activities, live independently, work for pay, or have prior antidepressant use. Continuers showed significantly greater early (3-month) improvement in global symptom severity. Logistic regression found that continuation was significantly predicted by longer illness duration, lower positive symptoms, higher negative symptoms, and better health-related quality of life.

Conclusions: In this large naturalistic study in Japan, most patients with schizophrenia stayed on olanzapine therapy for the full 1-year study period. Treatment completion with olanzapine was independently predicted by longer illness duration, lower positive symptoms, higher negative symptoms, and better health-related quality of life.

Keywords: schizophrenia, atypical, antipsychotics, discontinuation

\section{Introduction}

Schizophrenia is a chronic and disabling mental illness that is associated with cognitive, behavioral, social, and occupational impairments. ${ }^{1}$ The primary recommended treatment for the acute symptoms of schizophrenia is antipsychotic medication., ${ }^{2,3}$ When assessing outcomes from treatment with antipsychotic medication, a variety of domains have been studied, including the core symptoms of schizophrenia, ${ }^{4-6}$ functional outcomes, ${ }^{7,8}$ cognition, ${ }^{9,10}$ and health care resource use. ${ }^{11,12}$ However, a simple measure of treatment effectiveness that is relevant to different stakeholders and broadly reflects meaningful outcomes in usual clinical care is needed.

One overall measure of effectiveness for antipsychotic treatment outcome in schizophrenia is time to all-cause medication discontinuation, a measure that captures the medication's efficacy, safety, and tolerability from both patients' and 
physicians' perspectives. ${ }^{13,14}$ The Clinical Antipsychotic Trials of Intervention Effectiveness, a large, independent, publicly funded, randomized clinical trial in the USA, used time to all-cause medication discontinuation as its primary outcome variable. ${ }^{13,15}$ Similarly, the European First Episode Schizophrenia Trial also used this as the study's primary outcome variable. ${ }^{16}$ Patients who continue with an antipsychotic longer have been shown to have better clinical and functional outcomes and a reduced risk of relapse and hospitalization. ${ }^{12,13,17,18}$

Multiple studies have demonstrated that medication discontinuation is sensitive to differences in outcomes between antipsychotics. Olanzapine therapy in particular, has shown significantly lower rates of discontinuation than ziprasidone, ${ }^{13,15,19-22}$ quetiapine, ${ }^{13,15,21,23-29}$ risperidone, ${ }^{11-13,19,24,26,30-37}$ aripiprazole, ${ }^{4,27,38}$ as well as typical antipsychotics. ${ }^{7,9-12,13,16,19,24,26,35,39-44}$

Few studies have attempted to identify baseline characteristics of patients who stay longer on therapy in Japan. Previous studies outside of Japan have identified predictors of antipsychotic continuation in schizophrenia such as male gender, ${ }^{28,45,46}$ older age, ${ }^{13,25,28,47,48}$ fewer psychiatric hospitalizations, ${ }^{28}$ lack of substance-use disorder, ${ }^{47,49,50}$ better therapeutic alliance, ${ }^{49}$ greater reduction in symptoms, ${ }^{17,18}$ and greater improvements in health-related quality of life (HRQOL). ${ }^{17,18}$ Whether these findings generalize to the Japanese health care system, which utilizes inpatient treatment relatively frequently, ${ }^{51,52}$ is unclear. Using data from a 1-year naturalistic observational study of patients with schizophrenia in Japan, this study aimed to identify baseline characteristics that differentiate patients who completed 1 year of olanzapine therapy from patients who discontinued olanzapine therapy.

\section{Methods \\ Sample selection}

The data for this study came from the Olanzapine Post Marketing Surveillance (OPMS) study. OPMS was a large multicenter naturalistic 1-year study that took place in Japan and consisted of 1850 patients who met the study entry criteria. To be eligible to take part in the study, participants had to have been diagnosed with schizophrenia and to have initiated treatment with olanzapine. The diagnosis for schizophrenia was based on criteria in the fourth edition of the Diagnostic and Statistical Manual of Mental Disorders published by the American Psychiatric Association. ${ }^{1}$ During this naturalistic study, all treatment decisions, including the decision to initiate olanzapine, were left to the discretion of the treating physician. Study enrollment started in November 2003 and was completed in July 2004. The follow-up period for the study continued for 1 year after enrollment or until the patient discontinued the treatment with olanzapine. Data were collected at the baseline, 3-month, 6-month, and 12-month visits. The procedures were approved by the internal review boards at each of the participating institutions. Informed consent for this observational study was acquired based on the requirements at each institution.

\section{Measures and definitions}

The primary dependent variable in this study was a dichotomous variable indicating if a patient continued with or discontinued olanzapine before the end of the 1-year study. Patients who left the study were classified as discontinuing olanzapine.

In this observational study, simple noninvasive measures were chosen to limit interference with usual clinical practice. Patient symptomatology was measured using the Clinical Global Impression-Schizophrenia (CGI-SCH) scale. The CGI-SCH scale consists of ratings for positive, negative, cognitive, and depressive symptoms as well as a global severity rating. ${ }^{53}$ The ratings for the CGI-SCH scale are anchored and range from no symptoms (0) to severe symptoms (6). ${ }^{53}$ Assessment of the concurrent validity between the CGI-SCH and the Positive and Negative Syndrome Scale found that the validity coefficients ranged from 0.61 for depressive symptoms to 0.86 for positive symptoms, with the remaining coefficients ranging from $0.75-0.80 .{ }^{54}$

Consistent with prior research, treatment response was operationally defined based on the CGI-SCH Global Severity rating. ${ }^{55}$ For patients with a baseline score between 4 and 6 points, treatment response was defined as a 2-point improvement. For patients with a baseline score between 1 and 3, treatment response was defined as a 1-point improvement.

HRQOL was assessed using the European Quality of Life 5-Dimensions Visual Analog Scale (EQ-5D VAS). ${ }^{56}$ The EQ-5D VAS ranges from 0 to 100 and has demonstrated moderate concurrent validity (ranging from 32 to 62) with the various scales of the World Health Organization Quality of Life - Brief instrument. ${ }^{57}$

Prior medication use was coded with indicator variables (Yes/No) for each of the following medication classes: antipsychotics, anticholinergics, antidepressants, anxiolytics/ hypnotics, mood stabilizers, or other. The presence of a baseline medical comorbidity was coded based on the presence of any of the following conditions: hypertension, 
hyperlipidemia, hepatic dysfunction, renal dysfunction, or other. Participation in social activities was coded if the patient indicated they had participated in any social activities in the past 4 weeks. Working for pay was coded if the patient indicated working with income at baseline. Finally, living independently was coded if the patient indicated living independently at baseline rather than being hospitalized, homeless, living communally with persons caring for the patient, or living as a dependent family member.

\section{Statistical methods}

Differences in baseline patient characteristics were compared using $t$-tests for continuous variables and chi-square tests for categorical variables. Stepwise logistic regression was used to identify independent baseline predictors of continuing olanzapine therapy. Table 1 lists all of the baseline predictor variables available to the stepwise logistic regression model. However, the CGI-SCH Global Severity scale was excluded from the stepwise logistic regression due to multicolinearity with the subscales. The significance level was set at $\alpha=0.05$ and all analyses were completed using SAS 9.1.3 (SAS Institute Inc, Cary, NC).

\section{Results \\ Sample description}

The OPMS study registered and enrolled 1949 patients. This analysis utilized the $1850(94.9 \%)$ patients who met all study entry criteria: 27 were excluded for contract or registration violations, 20 had no case report forms, 49 did not return after the initial visit, and three did not initiate treatment with olanzapine. The baseline characteristics of this sample can be seen in Table 1. For the entire sample, the average age was $44.8 \pm 15.5$ years, $53.2 \%$ were male, $43.2 \%$ initiated olanzapine in an outpatient setting, and the average duration of illness was $18.3 \pm 14.7$ years. Most participants $(68.2 \%$; $1262 / 1850$ ) continued the olanzapine treatment for the full

Table I Baseline univariate characteristics

\begin{tabular}{|c|c|c|c|c|}
\hline Characteristic & Total $\mathbf{N}$ & $\begin{array}{l}\text { Discontinuer } \\
(N=588)\end{array}$ & $\begin{array}{l}\text { Continuer } \\
(N=1262)\end{array}$ & $P$ \\
\hline \multicolumn{5}{|l|}{ Demographics } \\
\hline Age $(y)$, mean $\pm S D$ & 1850 & $42.4 \pm 15.5$ & $45.9 \pm 15.4$ & $<0.001$ \\
\hline Female (\%) & 1850 & 51.0 & 44.8 & 0.013 \\
\hline \multicolumn{5}{|l|}{ Clinical status } \\
\hline Outpatient status (\%) & 1850 & 49.3 & 40.4 & $<0.001$ \\
\hline Duration of illness $(y)$, mean \pm SD & $|45|$ & $15.1 \pm 14.0$ & $19.7 \pm 14.9$ & $<0.001$ \\
\hline Tardive dyskinesia (\%) & 1822 & 5.2 & 7.7 & 0.052 \\
\hline $\mathrm{BMI}\left(\mathrm{kg} / \mathrm{m}^{2}\right)$, mean $\pm \mathrm{SD}$ & 1638 & $22.6 \pm 4.3$ & $22.6 \pm 4.0$ & 0.84 \\
\hline Any medical comorbidities (\%) & 1849 & 31.5 & 38.4 & 0.004 \\
\hline \multicolumn{5}{|l|}{ Clinical measures } \\
\hline CGI-SCH global severity, mean \pm SD & 1822 & $3.3 \pm 1.0$ & $3.4 \pm 1.1$ & 0.45 \\
\hline $\mathrm{CGI}-\mathrm{SCH}$ positive, mean $\pm \mathrm{SD}$ & 1822 & $3.1 \pm 1.5$ & $2.9 \pm 1.5$ & 0.052 \\
\hline CGI-SCH negative, mean \pm SD & 1822 & $2.9 \pm 1.4$ & $3.2 \pm 1.3$ & $<0.001$ \\
\hline CGI-SCH cognitive, mean \pm SD & 1822 & $2.8 \pm 1.4$ & $3.0 \pm 1.3$ & 0.004 \\
\hline CGI-SCH depressive, mean \pm SD & 1822 & $1.7 \pm 1.4$ & $1.6 \pm 1.3$ & 0.09 \\
\hline Responded at 3-month visit (\%) & 1822 & 28.9 & 36.0 & 0.003 \\
\hline \multicolumn{5}{|l|}{ Functional measures } \\
\hline EQ-5D VAS, mean \pm SD & 1815 & $43.6 \pm 21.3$ & $49.6 \pm 22.8$ & $<0.001$ \\
\hline Working for pay (\%) & 1820 & 12.0 & 7.5 & 0.007 \\
\hline Social activities (\%) & 1820 & 32.7 & 26.8 & 0.027 \\
\hline Living independently (\%) & 1822 & 20.4 & 15.7 & 0.014 \\
\hline \multicolumn{5}{|l|}{ Baseline and prior medication use } \\
\hline Starting dose of OLZ (mg/day), mean \pm SD & 1847 & $8.4 \pm 5.3$ & $8.6 \pm 5.0$ & 0.56 \\
\hline Switch from atypical antipsychotic (\%) & 1850 & 21.6 & 20.5 & 0.60 \\
\hline Switch from typical antipsychotic (\%) & 1850 & 13.3 & 15.2 & 0.27 \\
\hline Prior anticholinergic use (\%) & 1823 & 35.7 & 41.8 & 0.012 \\
\hline Prior antidepressant use (\%) & 1823 & 7.7 & 4.4 & 0.005 \\
\hline Prior anxiolytic/hypnotic use (\%) & 1823 & 57.6 & 60.5 & 0.24 \\
\hline Prior mood stabilizer use (\%) & 1823 & 13.0 & 12.9 & 0.93 \\
\hline Prior other medication use (\%) & 1823 & 32.2 & 44.9 & $<0.001$ \\
\hline
\end{tabular}

Abbreviations: BMI, body mass index; CGI-SCH, Clinical Global Impression-Schizophrenia; EQ-5D VAS, European Quality of Life 5-Dimensions Visual Analog Scale; OLZ, olanzapine; SD, standard deviation. 
1-year study, while $31.8 \%$; (588/1850) discontinued the study at some point (see Figure 1). The mean duration of olanzapine therapy during the 1 -year study treatment was $265.5 \pm 119.4$ days.

\section{Univariate comparisons between discontinuers and continuers}

Table 1 contrasts the baseline characteristics of patients who completed the 1-year study with olanzapine (continuers) with those who discontinued olanzapine treatment prior to the end of the study (discontinuers). Significant differences were observed in multiple demographics, clinical status variables, symptom measures, functional measures, and prior medication use variables (see Table 1).

\section{Multivariate comparisons between discontinuers and continuers}

Stepwise logistic regression was used to identify independent predictors of continuation. The odds ratios and confidence intervals for the final version of the stepwise logistic regression model are presented in Figure 2. Overall, the model was modestly accurate in differentiating patients who would continue or discontinue treatment with olanzapine $(\mathrm{c}$-statistic $=0.635)$. The $\mathrm{c}$-statistic indicated that the model could accurately classify a randomly selected continuer from a randomly selected discontinuer $63.5 \%$ of the time. Continuation was independently predicted by lower positive symptoms, higher negative symptoms, longer illness duration, and better HRQOL. All of the significant predictors were continuous variables; therefore, the odds ratios represent the change in odds of continuation for every one-unit increase in the predictor. For example, for every year that a patient had been diagnosed with schizophrenia, the odds of continuing with olanzapine increased by a factor of 1.01 .

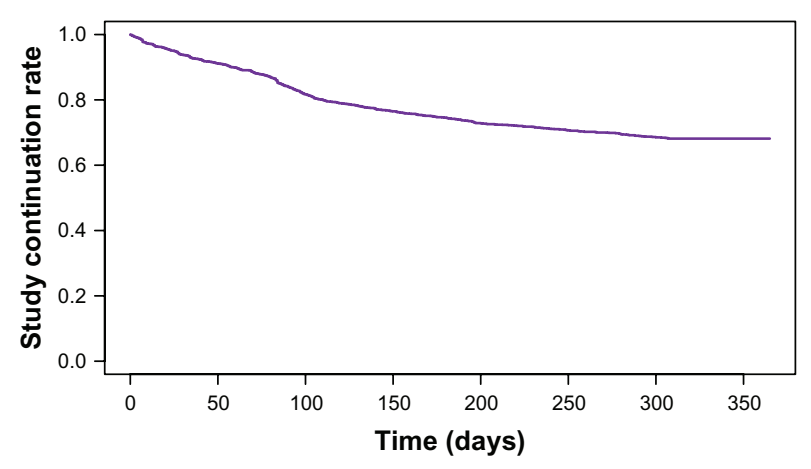

Figure I Proportion of patients continuing olanzapine for I year. Most patients $(68.2 \%, 1262 / 1850)$ continued with olanzapine treatment for the full I-year study. Note: The mean duration of olanzapine treatment was $265.5 \pm 119.4$ days.
Finally, early change in CGI-SCH Global Severity, defined as the difference between baseline and the first visit ( 3 months), was compared between the continuers and discontinuers. Patients who continued with olanzapine treatment experienced greater improvements (decreases) in CGISCH Global Severity compared to those who discontinued olanzapine therapy $(-0.69$ vs $-0.53 ; P=001)$.

\section{Discussion}

In this large naturalistic observational study of patients with schizophrenia in Japan, most patients (68.2\%) continued olanzapine therapy for the full 1-year study, with an average time to discontinuation of 265.5 days. A large number of baseline characteristics predicted the continuation in the univariate analyses, but only a few were found to be independent predictors in the multivariate analysis. In the stepwise logistic regression model, higher EQ-5D VAS scores, longer duration of illness, higher CGI$\mathrm{SCH}$ negative scores, and lower CGI-SCH positive scores were significant predictors of treatment continuation. The olanzapine continuers had significantly greater early improvements in CGI-SCH Global Severity scores than the discontinuers.

The findings in the current study are consistent with some past schizophrenia research with outpatients outside of Japan. In the univariate analysis, older age $\mathrm{e}^{13,25,27,47,48}$ and male gender ${ }^{28,44,46}$ predicted antipsychotic continuation. The primary findings in the multivariate analysis were also consistent with previous research on predictors of medication continuation: longer duration of illness,${ }^{45}$ higher baseline HRQOL,${ }^{58}$ higher baseline negative symptoms, ${ }^{58}$ and lower baseline positive symptom $\mathrm{s}^{59}$ have all been identified as predictors of antipsychotic continuation. Interestingly, in one study, lower baseline positive symptoms were reported to predict discontinuation rather than continuation. ${ }^{48}$ Inconsistencies in predictors of continuation may be a result of differences in study methodologies, outcome variables, the inclusion of inpatients, study population, or health care systems.

In addition to the identified patients' baseline characteristics, poorer efficacy of antipsychotic medications has also been linked to the discontinuation of treatment. In fact, past research has consistently identified lack of efficacy as being one of the primary reasons for antipsychotic discontinuation. ${ }^{13,17,21,26,45,60-63}$ Consistent with prior research, secondary analysis in the present study found that patients who continued antipsychotic treatment had greater reductions in symptoms. 


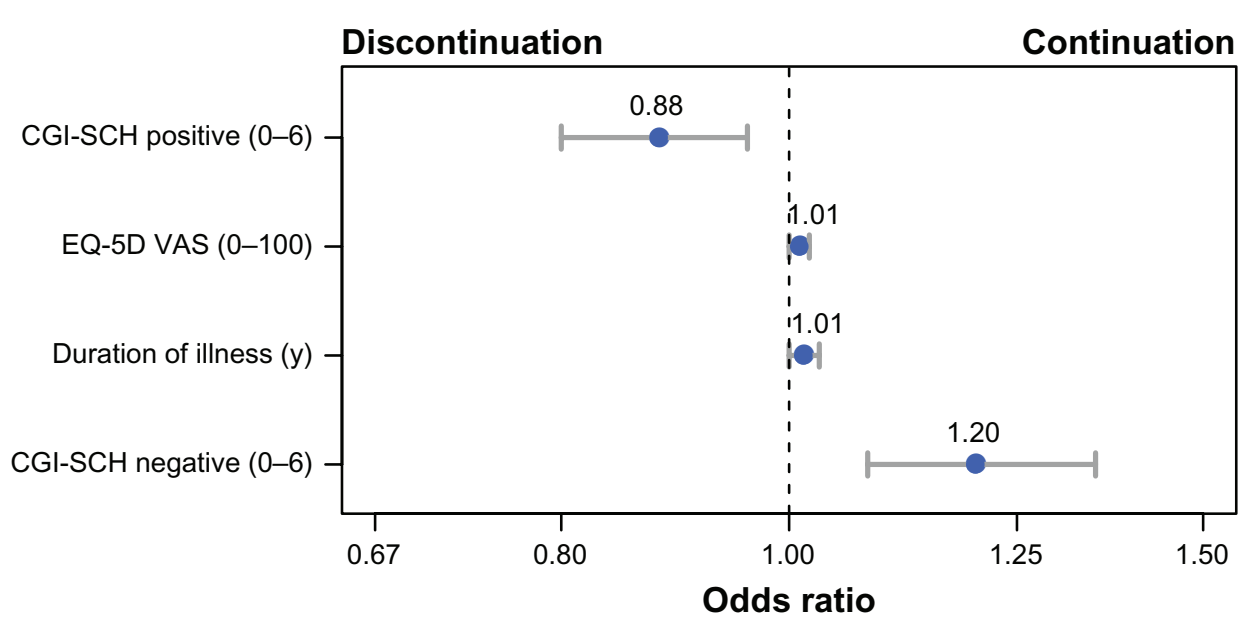

Figure 2 Significant predictors of treatment continuation in the stepwise logistic regression analysis. This figure presents the odds ratios and $95 \%$ confidence intervals for each of the predictors of continuation in the final stepwise logistic regression model. Each predictor in the final model was a continuous variable; therefore, the odds ratios represent the change in odds of continuation for every one-unit increase in the predictor variable.

Abbreviations: CGI-SCH, Clinical Global Impression-Schizophrenia; EQ-5D VAS, European Quality of Life 5-Dimensions Visual Analog Scale.

\section{Limitations}

Although a large number of predictors were used in this analysis, some potentially important predictors of antipsychotic persistence were not included in this study. A lower level of substance abuse has been frequently demonstrated as being an important predictor of antipsychotic persistence. . $^{47,49,50,63-67}$ Additionally, insight into illness ${ }^{67}$ as well as positive attitudes toward medication ${ }^{49,68}$ have been identified as being potentially important in the predictors of antipsychotic persistence. The primary focus of this analysis was on baseline predictors of later antipsychotic persistence. Changes in metabolic and other tolerability parameters were not included in the analyses and may be important predictors of antipsychotic persistence. Furthermore, the OPMS study focused only on olanzapine-treated patients with schizophrenia in Japan, so the findings may not generalize to other antipsychotics or geographic locations.

\section{Conclusion}

Consistent with prior research, patients who continued olanzapine therapy were more likely to experience significant improvements in clinical outcomes compared to those who discontinued treatment. ${ }^{18,69}$ In addition, patients with certain baseline characteristics appear to be more likely to continue with olanzapine treatment for a longer period of time. Stepwise logistic regression revealed that, compared to discontinuers, those who continued with olanzapine therapy had significantly longer illness duration, lower baseline positive symptoms, higher baseline negative symptoms, and higher baseline HRQOL. Identifying these characteristics has clinical implications in usual care in Japan, as they may be useful in early detection of schizophrenia patients who could benefit from targeted interventions aimed at improving their persistence with medication, thus increasing the chance for better long-term treatment outcomes.

\section{Acknowledgments}

Funding for this study was provided by Eli Lilly and Company. Technical writing support was provided by Michael Stensland of Agile Outcomes Research Inc, Rochester, MN, and Susan Dennett of Strategic Health Outcomes Inc, Carmel, IN.

\section{Disclosure}

Wenyu Ye is a full-time employee of Lilly Suzhou Pharmaceutical Co, Shanghai, People's Republic of China. Haya Ascher-Svanum is a full-time employee of Eli Lilly and Company, Indianapolis, IN, USA. Jennifer A Flynn and Yuka Tanji are full-time employees of Eli Lilly Japan, KK, Kobe, Japan. Michihiro Takahashi is a consultant for Eli Lilly Japan, KK. All authors are minor stockholders in Eli Lilly and Company.

\section{References}

1. American Psychiatric Association. Diagnostic and Statistical Manual of Mental Disorders DSM-IV-TR. 4th ed. Washington, DC: American Psychiatric Association; 2000.

2. Lehman AF, Lieberman JA, Dixon LB, et al. Practice guideline for the treatment of patients with schizophrenia, second edition. Am J Psychiatry. 2004;161(2 Suppl):1-56.

3. Falkai P, Wobrock T, Lieberman J, et al. World Federation of Societies of Biological Psychiatry (WFSBP) guidelines for biological treatment of schizophrenia, Part 1: acute treatment of schizophrenia. World J Biol Psychiatry. 2005;6(3):132-191. 
4. Fleischhacker WW, McQuade RD, Marcus RN, et al. A double-blind, randomized comparative study of aripiprazole and olanzapine in patients with schizophrenia. Biol Psychiatry. 2009;65(6):510-517.

5. Gureje O, Miles W, Keks N, et al. Olanzapine vs risperidone in the management of schizophrenia: a randomized double-blind trial in Australia and New Zealand. Schizophr Res. 2003;61(2-3): 303-314.

6. Tollefson GD, Beasley CM Jr, Tran PV, et al. Olanzapine versus haloperidol in the treatment of schizophrenia and schizoaffective and schizophreniform disorders: results of an international collaborative trial. Am J Psychiatry. 1997;154(4):457-465.

7. Jones PB, Barnes TR, Davies L, et al. Randomized controlled trial of the effect on Quality of Life of second- vs first-generation antipsychotic drugs in schizophrenia: Cost Utility of the Latest Antipsychotic Drugs in Schizophrenia Study (CUtLASS 1). Arch Gen Psychiatry. 2006; 63(10):1079-1087.

8. Perlick DA, Rosenheck RA, Kaczynski R, Bingham S, Collins J. Association of symptomatology and cognitive deficits to functional capacity in schizophrenia. Schizophr Res. 2008;99(1-3):192-199.

9. Keefe RS, Young CA, Rock SL, et al. One-year double-blind study of the neurocognitive efficacy of olanzapine, risperidone, and haloperidol in schizophrenia. Schizophr Res. 2006;81(1):1-15.

10. Purdon SE, Jones BD, Stip E, et al. Neuropsychological change in early phase schizophrenia during 12 months of treatment with olanzapine, risperidone, or haloperidol. Arch Gen Psychiatry. 2000;57(3): 249-258.

11. Gibson PJ, Damler R, Jackson EA, Wilder T, Ramsey JL. The impact of olanzapine, risperidone, or haloperidol on the cost of schizophrenia care in a medicaid population. Value Health. 2004;7(1):22-35.

12. Tunis SL, Faries DE, Nyhuis AW, et al. Cost-effectiveness of olanzapine as first-line treatment for schizophrenia: results from a randomized, open-label, 1-year trial. Value Health. 2006;9(2):77-89.

13. Lieberman JA, Stroup TS, McEvoy JP, et al. Effectiveness of antipsychotic drugs in patients with chronic schizophrenia. $N$ Engl $J$ Med. 2005;353(12):1209-1223.

14. Stroup TS, McEvoy JP, Swartz MS, et al. The National Institute of Mental Health Clinical Antipsychotic Trials of Intervention Effectiveness (CATIE) project: schizophrenia trial design and protocol development. Schizophr Bull. 2003;29(1):15-31.

15. Stroup TS, Lieberman JA, McEvoy JP, et al. Effectiveness of olanzapine, quetiapine, risperidone, and ziprasidone in patients with chronic schizophrenia following discontinuation of a previous atypical antipsychotic. Am J Psychiatry. 2006;163(4):611-622.

16. Kahn RS, Fleischhacker WW, Boter H, et al. Effectiveness of antipsychotic drugs in first-episode schizophrenia and schizophreniform disorder: an open randomised clinical trial. Lancet. 2008;371(9618): 1085-1097.

17. Liu-Seifert H, Osuntokun OO, Feldman PD. Factors associated with adherence to treatment with olanzapine and other atypical antipsychotic medications in patients with schizophrenia. Compr Psychiatry. [Epub ahead of print].

18. Davis SM, Stroup TS, Koch GG, et al. Time to all-cause treatment discontinuation as the primary outcome in the Clinical Antipsychotic Trials of Intervention Effectiveness (CATIE) Schizophrenia Study. Stat Biopharm Res. 2011;3(2):253-265.

19. Beasley CM Jr, Stauffer VL, Liu-Seifert H, et al. All-cause treatment discontinuation in schizophrenia during treatment with olanzapine relative to other antipsychotics: an integrated analysis. $J$ Clin Psychopharmacol. 2007;27(3):252-258.

20. Breier A, Berg PH, Thakore JH, et al. Olanzapine versus ziprasidone: results of a 28-week double-blind study in patients with schizophrenia. Am J Psychiatry. 2005;162(10):1879-1887.

21. Kinon BJ, Liu-Seifert H, Adams DH, Citrome L. Differential rates of treatment discontinuation in clinical trials as a measure of treatment effectiveness for olanzapine and comparator atypical antipsychotics for schizophrenia. J Clin Psychopharmacol. 2006;26(6): 632-637.
22. Strom BL, Eng SM, Faich G, et al. Comparative mortality associated with ziprasidone and olanzapine in real-world use among 18,154 patients with schizophrenia: The Ziprasidone Observational Study of Cardiac Outcomes (ZODIAC). Am J Psychiatry. 2011;168(2):193-201.

23. Deberdt W, Lipkovich I, Heinloth AN, et al. Double-blind, randomized trial comparing efficacy and safety of continuing olanzapine versus switching to quetiapine in overweight or obese patients with schizophrenia or schizoaffective disorder. Ther Clin Risk Manag. 2008;4(4):713-720.

24. Dossenbach M, Pecenak J, Szulc A, et al. Long-term antipsychotic monotherapy for schizophrenia: disease burden and comparative outcomes for patients treated with olanzapine, quetiapine, risperidone, or haloperidol monotherapy in a pan-continental observational study. J Clin Psychiatry. 2008;69(12):1901-1915.

25. Gianfrancesco F, Rajagopalan K, Sajatovic M, Wang RH. Treatment adherence among patients with schizophrenia treated with atypical and typical antipsychotics. Psychiatry Res. 2006;144(2-3):177-189.

26. Haro JM, Suarez D, Novick D, et al. Three-year antipsychotic effectiveness in the outpatient care of schizophrenia: observational versus randomized studies results. Eur Neuropsychopharmacol. 2007; 17(4):235-244.

27. Hatta K, Sato K, Hamakawa H, et al. Effectiveness of second-generation antipsychotics with acute-phase schizophrenia. Schizophr Res. 2009;113(1):49-55.

28. Mullins CD, Obeidat NA, Cuffel BJ, Naradzay J, Loebel AD. Risk of discontinuation of atypical antipsychotic agents in the treatment of schizophrenia. Schizophr Res. 2008;98(1-3):8-15.

29. Newcomer JW, Ratner RE, Eriksson JW, et al. A 24-week, multicenter, open-label, randomized study to compare changes in glucose metabolism in patients with schizophrenia receiving treatment with olanzapine, quetiapine, or risperidone. J Clin Psychiatry. 2009;70(4):487-499.

30. Cooper D, Moisan J, Gaudet M, Abdous B, Grégoire JP. Ambulatory use of olanzapine and risperidone: a population-based study on persistence and the use of concomitant therapy in the treatment of schizophrenia. Can J Psychiatry. 2005;50(14):901-908.

31. Kilzieh N, Todd-Stenberg JA, Kennedy A, Wood AE, Tapp AM. Time to discontinuation and self-discontinuation of olanzapine and risperidone in patients with schizophrenia in a naturalistic outpatient setting. $J$ Clin Psychopharmacol. 2008;28(1):74-77.

32. Rascati KL, Johnsrud MT, Crismon ML, Lage MJ, Barber BL. Olanzapine versus risperidone in the treatment of schizophrenia: a comparison of costs among Texas Medicaid recipients. Pharmacoeconomics. 2003;21(10):683-697.

33. Ren XS, Qian S, Lee AF, Herz L, Miller DR, Kazis LE. Treatment persistence: a comparison among patients with schizophrenia who were initiated on atypical antipsychotic agents. J Clin Pharm Ther. 2006; 31(1):57-65.

34. Stroup TS, Lieberman JA, McEvoy JP, et al. Effectiveness of olanzapine, quetiapine, and risperidone in patients with chronic schizophrenia after discontinuing perphenazine: a CATIE study. Am $J$ Psychiatry. 2007;164(3):415-427.

35. Tiihonen J, Haukka J, Taylor M, Haddad PM, Patel MX, Korhonen P. A nationwide cohort study of oral and depot antipsychotics after first hospitalization for schizophrenia. Am J Psychiatry. 2011;168(6): 603-609.

36. Yamakawa Y, Terashima Y, Tanoue Y, et al. [A survey to examine patterns of prescribing atypical antipsychotic drugs for outpatients with schizophrenia]. Jpn J Clin Psychopharmacol. 2010;13:1163-1176. Japanese.

37. Zhao Z. A retrospective economic evaluation of olanzapine versus risperidone in the treatment of schizophrenia. Manag Care Interface. 2002;15(2):75-81.

38. Kern RS, Green MF, Cornblatt BA, et al. The neurocognitive effects of aripiprazole: an open-label comparison with olanzapine. Psychopharmacology (Berl). 2006;187(3):312-320.

39. Ascher-Svanum H, Zhu B, Faries D, Landbloom R, Swartz M, Swanson J. Time to discontinuation of atypical versus typical antipsychotics in the naturalistic treatment of schizophrenia. BMC Psychiatry. 2006;6:8. 
40. Gerra G, Di Petta G, D’Amore A, et al. Combination of olanzapine with opioid-agonists in the treatment of heroin-addicted patients affected by comorbid schizophrenia spectrum disorders. Clin Neuropharmacol. 2007;30(3):127-135

41. Ishigooka J, Inada T, Miura S. Olanzapine versus haloperidol in the treatment of patients with chronic schizophrenia: results of the Japan multicenter, double-blind olanzapine trial. Psychiatry Clin Neurosci. 2001;55(4):403-414.

42. Lieberman JA, Tollefson G, Tohen M, et al. Comparative efficacy and safety of atypical and conventional antipsychotic drugs in first-episode psychosis: a randomized, double-blind trial of olanzapine versus haloperidol. Am J Psychiatry. 2003;160(8):1396-1404.

43. Marshall TS, McCombs JS, Stafkey-Mailey D. Impact of patient selection criteria and treatment history on comparisons of alternative therapies: a case study of atypical antipsychotics. Value Health. 2009; 12(4):473-480

44. Tiihonen J, Wahlbeck K, Lönnqvist J, et al. Effectiveness of antipsychotic treatments in a nationwide cohort of patients in community care after first hospitalisation due to schizophrenia and schizoaffective disorder: observational follow-up study. BMJ. 2006;333(7561):224.

45. Hodgson R, Belgamwar R, Al-tawarah Y, MacKenzie G. The use of atypical antipsychotics in the treatment of schizophrenia in North Staffordshire. Hum Psychopharmacol. 2005;20(2):141-147.

46. Jung SH, Kim WH, Choi HJ, et al. Factors affecting treatment discontinuation and treatment outcome in patients with schizophrenia in Korea: 10-year follow-up study. Psychiatry Investig. 2011;8(1): 22-29.

47. Kreyenbuhl J, Slade EP, Medoff DR, et al. Time to discontinuation of first- and second-generation antipsychotic medications in the treatment of schizophrenia. Schizophr Res. 2011;131(1-3):127-132.

48. Gaebel W, Riesbeck M, von Wilmsdorff M, et al. Drug attitude as predictor for effectiveness in first-episode schizophrenia: results of an open randomized trial (EUFEST). Eur Neuropsychopharmacol. 2010;20(5):310-316.

49. Tunis SL, Faries DE, Stensland MD, Hay DP, Kinon BJ. An examination of factors affecting persistence with initial antipsychotic treatment in patients with schizophrenia. Curr Med Res Opin. 2007;23(1):97-104.

50. Chang CL, Tzeng DS, Lung FW. Treatment effectiveness and adherence in patients with schizophrenia treated with risperidone long-acting injection. Psychiatry Res. 2010;180(1):16-19.

51. Shinfuku N, Tan CH. Pharmacotherapy for schizophrenic inpatients in East Asia - changes and challenges. Int Rev Psychiatry. 2008;20(5): 460-468.

52. Oshima I, Mino Y, Inomata Y. How many long-stay schizophrenia patients can be discharged in Japan? Psychiatry Clin Neurosci. 2007; 61(1):71-77.

53. Haro JM, Kamath SA, Ochoa S, et al. The Clinical Global ImpressionSchizophrenia scale: a simple instrument to measure the diversity of symptoms present in schizophrenia. Acta Psychiatr Scand Suppl. 2003;(416):16-23.

54. Kay SR, Fiszbein A, Opler LA. The positive and negative syndrome scale (PANSS) for schizophrenia. Schizophr Bull. 1987;13(2):261-276.

55. Haro JM, Edgell ET, Novick D, et al. Effectiveness of antipsychotic treatment for schizophrenia: 6-month results of the Pan-European Schizophrenia Outpatient Health Outcomes (SOHO) study. Acta Psychiatr Scand. 2005;111(3):220-231.
56. EuroQol - a new facility for the measurement of health-related quality of life. The EuroQol Group. Health Policy. 1990;16(3):199-208.

57. König HH, Roick C, Angermeyer MC. Validity of the EQ-5D in assessing and valuing health status in patients with schizophrenic, schizotypal or delusional disorders. Eur Psychiatry. 2007;22(3):177-187.

58. Nyhuis AW, Faries DE, Ascher-Svanum H, Stauffer VL, Kinon BJ. Predictors of switching antipsychotic medications in the treatment of schizophrenia. BMC Psychiatry. 2010;10:75.

59. Haro JM, Novick D, Suarez D, Roca M. Antipsychotic treatment discontinuation in previously untreated patients with schizophrenia: 36-month results from the SOHO study. J Psychiatr Res. 2009;43(3): 265-273.

60. Kahn R, Fleischhacker WW, Boter H, et al. Effectiveness of antipsychotic drugs in first-episode schizophrenia and schizophreniform disorder: an open randomised clinical trial. Lancet. 2008;371(9618): 1085-1097.

61. Kinon BJ, Lipkovich I, Edwards SB, et al. A 24-week randomized study of olanzapine versus ziprasidone in the treatment of schizophrenia or schizoaffective disorder in patients with prominent depressive symptoms. J Clin Psychopharmacol. 2006;26(2):157-162.

62. Liu-Seifert H, Adams DH, Kinon BJ. Discontinuation of treatment of schizophrenic patients is driven by poor symptom response: a pooled post-hoc analysis of four atypical antipsychotic drugs. BMC Med. 2005;3:21

63. Perkins DO, Gu H, Weiden PJ, et al. Predictors of treatment discontinuation and medication nonadherence in patients recovering from a first episode of schizophrenia, schizophreniform disorder, or schizoaffective disorder: a randomized, double-blind, flexible-dose, multicenter study. J Clin Psychiatry. 2008;69(1):106-113.

64. Ascher-Svanum H, Nyhuis A, Faries D, Heiler L, Kinon B. Treatment discontinuation following randomization to open-label olanzapine, risperidone or typical antipsychotics during a one-year treatment for schizophrenia. Clin Schizophr Relat Psychoses. 2008;2(3):226-234.

65. Gilmer TP, Dolder CR, Folsom DP, Mastin W, Jeste DV. Antipsychotic polypharmacy trends among Medicaid beneficiaries with schizophrenia in San Diego County, 1999-2004. Psychiatr Serv. 2007; 58(7):1007-1010.

66. Novick D, Haro JM, Suarez D, Perez V, Dittmann RW, Haddad PM. Predictors and clinical consequences of non-adherence with antipsychotic medication in the outpatient treatment of schizophrenia. Psychiatry Res. 2010;176(2-3):109-113.

67. Valenstein M, Ganoczy D, McCarthy JF, Myra Kim H, Lee TA, Blow FC. Antipsychotic adherence over time among patients receiving treatment for schizophrenia: a retrospective review. J Clin Psychiatry. 2006;67(10):1542-1550.

68. Lacro JP, Dunn LB, Dolder CR, Leckband SG, Jeste DV. Prevalence of and risk factors for medication nonadherence in patients with schizophrenia: a comprehensive review of recent literature. J Clin Psychiatry. 2002;63(10):892-909.

69. Dunayevich E, Ascher-Svanum H, Zhao F, et al. Longer time to antipsychotic treatment discontinuation for any cause is associated with better functional outcomes for patients with schizophrenia, schizophreniform disorder, or schizoaffective disorder. $J$ Clin Psychiatry. 2007;68(8):1163-1171

\section{Dovepress}

\section{Publish your work in this journal}

Patient Preference and Adherence is an international, peer-reviewed, open access journal focusing on the growing importance of patient preference and adherence throughout the therapeutic continuum. Patient satisfaction, acceptability, quality of life, compliance, persistence and their role in developing new therapeutic modalities and compounds to

optimize clinical outcomes for existing disease states are major areas of interest. This journal has been accepted for indexing on PubMed Central. The manuscript management system is completely online and includes a very quick and fair peer-review system. Visit http://www.dovepress.com/ testimonials.php to read real quotes from published authors. 